\title{
Initial diagnosis and management of chronic obstructive pulmonary disease in Australia: views from the coal face
}

\section{Author details:}

Bonnie Bereznicki, Lecturer - University of Tasmania, Hobart, Tasmania

(author contribution: 60\%)

Haydn Walters, Professorial Fellow - University of Tasmania, Hobart, Tasmania

(author contribution: 10\%);

Julia Walters, Senior Research Fellow - University of Tasmania, Hobart, Tasmania

(author contribution: 10\%);

Gregory Peterson, Associate Dean (Research) - University of Tasmania, Hobart,

Tasmania (author contribution: 10\%);

Luke Bereznicki, Deputy Head (Medicine) - University of Tasmania, Hobart, Tasmania

(author contribution: 10\%)

Authors' affiliation: School of Medicine, University of Tasmania

\section{Corresponding author:}

Bonnie Bereznicki

School of Medicine (Pharmacy), University of Tasmania

Private Bag 26 Hobart TAS 7001

Email: Bonnie.Bereznicki@utas.edu.au

Telephone: 0362264624

\section{Acknowledgements:}

This study was funded by the University of Tasmania's Faculty of Health's strategic seed funding scheme.

\begin{abstract}
:
Background: Early diagnosis and management can mitigate the long-term morbidity and mortality of chronic obstructive pulmonary disease (COPD).

Aim: To gain insights into the initial diagnostic process and early management of COPD by Australian general practitioners (GPs).

Methods: A random sample of Australian GPs was invited to complete a postal survey, which assessed familiarity with and use of contemporary practice guidelines, diagnostic criteria, and management preferences for COPD.

Results: Two hundred and thirty-three GPs completed the survey. While most GPs based a COPD diagnosis on smoking history (94.4\%), symptoms $(91.0 \%)$ and spirometry $(88.8 \%$ ), only $39.9 \%$ of respondents recorded a formal diagnosis of COPD after the patient's first symptomatic presentation. Tiotropium was the preferred treatment in $77.3 \%$ of GPs for the initial management of COPD, while only $27.5 \%$ routinely recommended pulmonary rehabilitation. GPs routinely recorded patients' smoking status and offered smoking cessation advice, but the timing of this advice varied. Less than half of the respondents routinely used COPD management guidelines, or tools and resources provided by the Australian Lung Foundation.

Conclusion: There is scope for major improvement in GPs' familiarity with and use of COPD management guidelines, and readily available tools and resources. Some
\end{abstract}

This article has been accepted for publication and undergone full peer review but has not been through the copyediting, typesetting, pagination and proofreading process, which may lead to differences between this version and the Version of Record. Please cite this article as doi: 10.1111/imj.13418

This article is protected by copyright. All rights reserved. 
systematic issues were highlighted in the Australian primary care setting, such as a reactive and relatively passive and delayed approach to diagnosis, potentially delayed smoking cessation advice and under-utilisation of pulmonary rehabilitation. There is an urgent need to devise strategies for improving patient outcomes in COPD using resources that are readily available.

\author{
Keywords: \\ Pulmonary Disease, Chronic Obstructive \\ General Practice \\ Guideline Adherence \\ Diagnosis \\ Disease management
}

\title{
Introduction
}

Chronic obstructive pulmonary disease (COPD), which is largely a preventable smoking-related condition, is a major cause of disability, hospital admission and premature death in Australia. Approximately 2 million Australians are estimated to have $\mathrm{COPD},{ }^{1}$ and the prevalence is likely to escalate as the population ages.

Early diagnosis and appropriate management will slow the progression of COPD. ${ }^{2}$ For a disease where decline is largely preventable, the sight of patients dying slowly of COPD should be a rarity - sadly it is becoming more common. ${ }^{2}$ COPD is the fourth leading cause of death worldwide and by 2020 it is estimated that it will be the third leading cause of death. ${ }^{3}$ Depending on disease severity, between $40-70 \%$ of patients with COPD will die within five years of being diagnosed, indicating how late substantive diagnosis is established. ${ }^{4}$

Under-diagnosis and under-treatment of COPD contribute significantly to the burden of human misery and healthcare costs. Despite widely distributed evidence-based management guidelines, ${ }^{5,6}$ knowledge of and adherence to these guidelines amongst

This article is protected by copyright. All rights reserved. 
doctors remains suboptimal. ${ }^{7-12}$ In Australia, more than $40 \%$ of patients with COPD do not have a formal diagnosis from their doctors, and less than $50 \%$ have ever been prescribed medication for their breathing and are taking the important steps critical to slow disease progression. ${ }^{11}$ Primary healthcare professionals need to know about the importance of early detection and management of COPD in order to ensure effective strategies are implemented to stop people with early disease progressing.

While previous studies involving patients with COPD in Australia have suggested suboptimal management, ${ }^{11,13}$ there is a lack of research involving practising Australian community-based general practitioners (GPs). The aim of this study was to gain insights into the initial diagnosis and early management practices for COPD amongst Australian primary care GPs, and to highlight any problem areas and management gaps, as determined by comparison with international-standard evidence-based management guidelines.

\section{Methods:}

A national postal questionnaire of Australian GPs was conducted. A total random sample of 1,000 GPs was approached; they were selected via the Medical Directory of Australia, an online medical database used to search and locate doctors and health facilities nationwide. ${ }^{14}$ The randomisation was undertaken independently by AMPCo Direct (Australasian Medical Publishing Company Ltd, Sydney).

These selected GPs were sent an invitation letter and the survey. Replies were returned via an enclosed postage paid envelope. A follow-up reminder letter was sent to all the doctors three weeks after the initial letter was sent. The survey was 4 pages in length, and contained a total of 32 questions. All items were checkbox questions, except for the final item which allowed any additional comments relating to COPD diagnosis and 
management. Completion of the survey was estimated to take approximately 10 minutes. The survey included questions about GP demographics and practice details, familiarity with contemporary practice guidelines, diagnosis of COPD, use of lung function tests, treatment preferences, advice offered and patient follow-up. A prize draw of an iPad mini was used as a recruitment incentive (to maintain anonymity, prize draw details were separated from survey responses immediately upon receipt).

De-identified surveys were collected from June to October 2014. All variables were collated and entered into a statistical software package, SPSS version 21 (IBM, Armonk, New York, US). Respondents were classified as adherent or non-adherent to management guidelines according to their responses to four management areas: (i) using smoking history and spirometry to diagnose COPD, (ii) preferring bronchodilators (not inhaled corticosteroids) for initial treatment of COPD, (iii) routinely recommending pulmonary rehabilitation to patients with COPD and (iv) routinely offering smoking cessation advice to patients with smoking-related COPD. ${ }^{5,6}$ Those classified as adherent had to be following the recommendations in all four areas.

Comparisons between adherent and non-adherent respondents were tested using the Chi Square test for dichotomous variables (with Yates' Correction for Continuity) and the Mann-Whitney test for continuous variables, with $P$ values of $<0.05$ deemed statistically significant. A logistic regression analysis was performed to assess the validity of guideline adherence by looking at the impact of potentially related factors, with $P<0.1$ used as a threshold for entry into the model. Variables that were used to classify respondents as adherent or non-adherent were excluded from the model. Variables that were closely related to adherence (e.g. views about spirometry and timing

This article is protected by copyright. All rights reserved. 
of smoking cessation advice) were also excluded from the model. The study was approved by the Tasmanian Social Sciences Human Research Ethics Committee.

\section{Results:}

Of the 1,000 surveys distributed, $233(23.3 \%)$ were completed and returned. The respondents were practicing in New South Wales (36.1\%), Victoria $(21.9 \%)$, Queensland (15.0\%), Western Australia (10.3\%), South Australia (8.2\%), Tasmania (5.2\%), Australian Capital Territory (0.4\%) and the Northern Territory (0.9\%). Most GPs practiced in an urban location $(82.0 \%)$, and had a practice nurse present in the practice at which they worked (91.4\%) (Table 1).

The respondents used a variety of tools to diagnose COPD, with the majority basing a diagnosis on smoking history $(94.4 \%)$, symptoms $(91.0 \%)$, spirometry $(88.8 \%)$ and physical examination (79.0\%). Most respondents either had direct access to a spirometer $(78.1 \%)$ or referred patients elsewhere for spirometry $(20.2 \%)$, and $98.3 \%$ believed that spirometry testing is helpful in guiding a diagnosis. However, only $39.9 \%$ of respondents indicated that they record a formal diagnosis of COPD after the patient's first presentation to them, with many GPs delaying the diagnosis until after a trial of pharmacotherapy (40.8\%), after a respiratory specialist has made a diagnosis $(20.2 \%)$ or after a diagnosis was made at hospital discharge (4.7\%).

While the majority $(87.6 \%)$ of GPs indicated that they routinely communicate the diagnosis to patients, $31.8 \%$ used terms other than 'chronic obstructive pulmonary disease' or 'COPD' in this communication. The majority $(88.8 \%)$ of respondents indicated that they routinely schedule follow-up visits with newly diagnosed patients (Table 2).

This article is protected by copyright. All rights reserved. 
The majority (93.1\%) of respondents believed that spirometry testing is helpful in guiding the management of COPD. Tiotropium was the preferred drug treatment in initial management by $77.3 \%$ of GPs, followed by short-acting beta- 2 agonists $(39.5 \%)$, inhaled corticosteroids (33.9\%) and long-acting beta-2 agonists (29.6\%). However, only $27.5 \%$ indicated that they routinely recommend the non-pharmacological management option of pulmonary rehabilitation. Most GPs indicated that they routinely record patients' smoking status (98.7\%) and offer smoking cessation advice, but the timing of this advice varied, with $78.1 \%$ offering advice on a patient's first presentation with respiratory symptoms, $11.2 \%$ waiting until a diagnosis of COPD has been made, $6.9 \%$ waiting until a follow-up visit and 3\% waiting until the patient expresses an interest in quitting. (Table 3).

Less than half $(48.9 \%)$ of the respondents indicated that their management of COPD is informed by guidelines. The Australian COPD-X guidelines were the most popular resource used (30.0\%), followed by the Therapeutic Guidelines (6.9\%). Three-quarters (75.1\%) of respondents indicated that they are aware of clinical tools and resources provided by the Australian Lung Foundation, but only $48.9 \%$ indicated that they routinely used these aids, and only $7.3 \%$ indicated that they were personally familiar with them (Table 4). Use of the chronic disease management GP services items available for reimbursement on the Medicare Benefits Schedule varied amongst respondents, with $41.2 \%$ indicating that they routinely use the General Practice Management Plan item and 36.5\% routinely using the Team Care Arrangement Plan item.

In total, $106(45.5 \%)$ respondents could be classified as adherent to all four practice guideline areas of diagnosis, pharmacological management, pulmonary rehabilitation 
and smoking cessation advice. Comparisons between GPs classed as adherent and nonadherent to management guidelines are shown in Table 5. GPs who were adherent to management guidelines were more likely to report the presence of a regular nurse at their practice who routinely saw patients with $\operatorname{COPD}(P=0.049)$, use the term 'chronic obstructive pulmonary disease' or 'COPD' when describing the diagnosis to patients $(P=0.081)$, use the General Practice Management Plan item $(P=0.002)$ and the Team Care Arrangement Plan item $(P<0.001)$, and be familiar with $(P=0.004)$ and routinely use $(P=0.011)$ the Australian Lung Foundation's tools and resources for GPs. The logistic regression model to predict the level of guideline adherence contained 7 variables and was statistically significant overall $\left(\chi^{2}=22.1, \mathrm{df}=7, P=0.002\right)$; however, no independent variables made an independent uniquely significant contribution to the model.

\section{Discussion:}

Recent studies have demonstrated that the most rapid decline in lung function in COPD may occur in early to moderate disease, ${ }^{15,16}$ suggesting that diagnosing and treating patients early in their disease trajectory may offer the best chance at mitigating the substantial long-term morbidity and mortality associated with COPD. However, COPD is still underdiagnosed and undertreated in most countries, especially in its early stages. ${ }^{11,17-19}$ The present study indicates that COPD is often not diagnosed and managed in Australian primary care per the most recent recommendations and guidelines, and readily available resources are widely underutilised. Diagnosis of COPD is uniformly reactive, with no obvious attempt to case-find COPD among asymptomatic smokers.

This article is protected by copyright. All rights reserved. 
While most GPs indicated that they base a diagnosis on smoking history, symptoms and spirometry, which is in accordance with guidelines, many GPs indicated that they often delay the diagnosis until after a trial of pharmacotherapy, after a respiratory specialist has made a diagnosis or after a hospital discharge diagnosis. This passive approach to diagnosis is consistent with other findings demonstrating that among patients meeting guideline criteria for COPD, many do not have a formal diagnosis from their GP, and are not receiving any treatment. ${ }^{11,19}$

Interestingly, a previous qualitative study of GPs found that delayed diagnosis of COPD by GPs may be intentional, rationalised by a misperception of patients' unwillingness to be given a diagnosis and GPs' nihilistic attitudes to prognosis. ${ }^{20}$ However, it is now known that pharmacologic therapy initiated early in the course of COPD (in addition to smoking cessation) may alter the rate of disease progression. ${ }^{21-23}$ Establishing and acting on an early diagnosis of COPD is therefore a critical step in reducing the extensive morbidity and mortality of this disease. Achieving the goal of early diagnosis in COPD is clearly a significant challenge. While a number of studies have demonstrated the effectiveness of case-finding programs in general practice to diagnose COPD early, ${ }^{24-28}$ a number of barriers reduce the implementation of such programs, including increased workload, and the need for assistance and financial compensation. ${ }^{29,30}$ Prescribing preferences in the initial management of COPD were generally in accordance with guidelines, with most GPs indicating that they prescribed bronchodilators. However, ICS seemed to be over-prescribed, with one-third of GPs indicating that they were prescribed in addition to bronchodilators as initial therapy in early disease. While ICS have been shown to improve quality of life and lung function when added to bronchodilator therapy, ${ }^{31}$ they have been shown to increase the risk of 
pneumonia in patients with COPD, ${ }^{32,33}$ and national management guidelines recommend that ICS be reserved for reduction in exacerbation rates in patients experiencing these frequently. ${ }^{5}$ Other studies around the world have also demonstrated ICS overuse in COPD, demonstrating suboptimal compliance with national and international guidelines. $^{10,34-36}$

Disappointingly, less than $30 \%$ of respondents indicated that they routinely recommend pulmonary rehabilitation to patients with COPD. While the reasons for this were not fully explored in this study, previous research suggests that low awareness of the health benefits of pulmonary rehabilitation and lack of availability of programs (or lack of knowledge about them) locally may be barriers to referral. ${ }^{12,37}$ Further strategies to enhance GPs' access to, awareness and familiarity with pulmonary rehabilitation, to improve referral rates are warranted.

GPs routinely recorded patients' smoking status and offer smoking cessation advice, but the timing of this advice varied, with more than $20 \%$ of respondents indicating that they delayed smoking cessation advice, even once the patient had presented with respiratory symptoms, variably waiting until a diagnosis of COPD has been made, at some illdefined follow-up appointment, or only when the patient expresses an interest in quitting, whenever socially appropriate or after an infective exacerbation. This delay may be due to patient-based or GP-based barriers to providing opportunistic smoking cessation advice, such as the patient's lack of motivation to quit, or time constraints, both of which have been described in previous research. ${ }^{38,39}$ While it is encouraging that almost $100 \%$ of respondents routinely offer smoking cessation advice to their patients, there is some room for improvement in when this advice is first offered, especially

This article is protected by copyright. All rights reserved. 
considering that early smoking cessation in COPD has been shown to have a greater impact on lung function decline. ${ }^{40}$

Less than half of the respondents indicated that their management of COPD is informed by guidelines. This is comparable to other studies outside of Australia. ${ }^{8,12}$ Increased awareness and implementation of guidelines and resources may improve screening of patients at risk and allow for earlier diagnosis of COPD. However, increased awareness and dissemination of guidelines alone may not necessarily translate into greater incorporation of such guidelines into practice. This was evidenced by three-quarters of respondents being aware of the Australian Lung Foundation's tools and resources for GPs, but less than half indicating that they routinely use them in practice. The lack of personal familiarity with resources is of special concern. The Australian Lung Foundation has developed a range of clinical resources deigned to support general practice in the diagnosis and management of COPD; however, our results suggest a need for better ways of getting GPs familiar with and using their COPD management tools.

There are some potential limitations to this study. The analysable response rate was only $23 \%$ and so the data may not have provided a true representation of GPs' practices. However, the response rate was typical of other surveys of doctors' treatment practices, ${ }^{41-43}$ and was considered acceptable for this form of research, especially given the relatively long questionnaire ( 32 questions). ${ }^{44}$ Nevertheless, it should be borne in mind that the results may underestimate any evidence-to-practice gaps in Australia, as it is reasonable to assume that GPs may have been less likely to respond if they were uninterested in COPD, or unsure of or did not adhere to, current COPD management guidelines.

This article is protected by copyright. All rights reserved. 
Notwithstanding these limitations, the results of this study provide valuable information regarding Australian prescribing and management practices in COPD. While previous studies involving patients with COPD in Australia have suggested suboptimal

management, ${ }^{11,13}$ to our knowledge this is the first study to gain insight into these clinical issues from practising Australian GPs.

\section{Conclusion:}

There is considerable scope for major overall improvement in GPs' use of and familiarity with COPD management guidelines, and the readily available tools and resources. The findings of this study highlight the need to devise strategies for improving clinical standards and so patient outcomes in COPD, and importantly by better use of resources already readily available. Compilation and dissemination of guidelines and focused education on some areas in need of improvement (such as delayed diagnosis, delayed smoking cessation advice and underutilisation of pulmonary rehabilitation) are important strategies for improving patient outcomes in COPD. Research in how to do all this more effectively should be a core part of any strategy, and should be recognised as a challenge for both the medical profession itself, and allied agencies such as the Australian Lung Foundation which produce the material that is so relatively under- or misused.

\section{Acknowledgements:}

This study was funded by the University of Tasmania's Faculty of Health's strategic seed funding scheme.

This article is protected by copyright. All rights reserved. 


\section{References:}

1 Access Economics Pty Ltd. Economic impact of COPD and cost effective solutions [homepage on the Internet]. Brisbane: The Australian Lung Foundation; 2008 [cited: 12 November 2016]. Available from:

http://www.rah.sa.gov.au/thoracic/health_programs/documents/EconomicImpacto fCOPDandCostEffectiveSolution_000.pdf.

2 Jones R. Can early diagnosis and effective management combat the irresistible rise of COPD? Br J Gen Pract. 2006; 56(530): 652-654.

3 World Health Organisation. World Health Statistics [homepage on the Internet]. Geneva: World Health Organisation; 2008 [cited: 12 November 2016]. Available from: http://www.who.int/whosis/whostat/2008/en/index.html.

4 Nishimura K, Tsukino M. Clinical course and prognosis of patients with chronic obstructive pulmonary disease. Current Opin Pulm Med. 2000; 6(2): 127-132.

5 Abramson M, Crockett AJ, Dabscheck E, Frith PA, George J, Glasgow N, Jenkins S, McDonald C, McDonald V, McKenzie DK, Wood-Baker R, Yang I, Zwar N. The COPD-X Plan: Australian and New Zealand Guidelines for the management of Chronic Obstructive Pulmonary Disease [homepage on the Internet]. Lung Foundation Australia and Thoracic Society of Australia and New Zealand; 2015 [cited: 12 November 2016]. Available from: http://www.copdx.org.au/.

6 Global Initiative for Chronic Obstructive Lung Disease (GOLD). Global Strategy for the Diagnosis, Management and Prevention of COPD [homepage on the Internet]. Global Initiative for Chronic Obstructive Lung Disease; 2016 [cited: 12 November 2016]. Available from: http://goldcopd.org/.

This article is protected by copyright. All rights reserved. 
7 Rutschmann OT, Janssens JP, Vermeulen B, Sarasin FP. Knowledge of guidelines for the management of COPD: a survey of primary care physicians. Respir Med. 2004; 98(10): 932-937.

8 Barr RG, Celli BR, Martinez FJ, Ries AL, Rennard SI, Reilly JJ, Jr., et al. Physician and patient perceptions in COPD: the COPD Resource Network Needs Assessment Survey. Am J Med. 2005; 118(12): 1415.e1419-1415.e1417.

9 Phanareth K, Hansen LS, Christensen LK, Laursen LC, Hansen EF. Treatment of acute severe asthma and chronic obstructive pulmonary disease in Danish hospitals. Do national recommendations improve on the quality of the treatment? Respir Med. 2002; 96(9): 653-658.

10 Roche N, Lepage T, Bourcereau J, Terrioux P. Guidelines versus clinical practice in the treatment of chronic obstructive pulmonary disease. Eur Respir J. 2001; 18(6): 903-908.

11 Matheson MC, Abeysena C, Raven JM, Skoric B, Johns DP, Abramson MJ, et al. How have we been managing chronic obstructive pulmonary disease in Australia? Intern Med J. 2006; 36(2): 92-99.

12 Yawn BP, Wollan PC. Knowledge and attitudes of family physicians coming to COPD continuing medical education. Int J Chron Obstruct Pulmon Dis. 2008; 3(2): 311-317.

13 Ta M, George J. Management of chronic obstructive pulmonary disease in Australia after the publication of national guidelines. Intern Med J. 2011; 41(3): 263-270.

This article is protected by copyright. All rights reserved. 
14 Australasian Medical Publishing Company [homepage on the Internet]. Medical Directory of Australia - MDA online [cited: November 12 2016]. Available from: https://www.mda.com.au/.

15 Drummond MB, Hansel NN, Connett JE, Scanlon PD, Tashkin DP, Wise RA. Spirometric predictors of lung function decline and mortality in early chronic obstructive pulmonary disease. Am J Respir Crit Care Med. 2012; 185(12): 13011306.

16 Tantucci C, Modina D. Lung function decline in COPD. Int J Chron Obstruct Pulmon Dis. 2012; 7:95-99.

17 Frank TL, Hazell ML, Linehan MF, Frank PI. The diagnostic accuracies of chronic obstructive pulmonary disease (COPD) in general practice: The results of the MAGIC (Manchester Airways Group Identifying COPD) study. Prim Care Respir J. 2006; 15(5): 286-293.

18 Pena VS, Miravitlles M, Gabriel R, Jimenez-Ruiz CA, Villasante C, Masa JF, et al. Geographic variations in prevalence and underdiagnosis of COPD: results of the IBERPOC multicentre epidemiological study. Chest. 2000; 118(4): 981-989.

19 Bednarek M, Maciejewski J, Wozniak M, Kuca P, Zielinski J. Prevalence, severity and underdiagnosis of COPD in the primary care setting. Thorax. 2008; 63(5): 402-407.

20 Walters JA, Hansen EC, Walters EH, Wood-Baker R. Under-diagnosis of chronic obstructive pulmonary disease: a qualitative study in primary care. Respir Med. 2008; 102(5): 738-743.

21 Decramer M, Celli B, Kesten S, Lystig T, Mehra S, Tashkin DP. Effect of tiotropium on outcomes in patients with moderate chronic obstructive pulmonary

This article is protected by copyright. All rights reserved. 
disease (UPLIFT): a prespecified subgroup analysis of a randomised controlled trial. Lancet. 2009; 374(9696): 1171-1178.

22 Jenkins CR, Jones PW, Calverley PM, Celli B, Anderson JA, Ferguson GT, et al. Efficacy of salmeterol/fluticasone propionate by GOLD stage of chronic obstructive pulmonary disease: analysis from the randomised, placebo-controlled TORCH study. Respir Res. 2009; doi: 10.1186/1465-9921-10-59.

23 Cukic V, Lovre V, Ustamujic A. The changes of pulmonary function in COPD during four-year period. Mater Sociomed. 2013; 25(2): 88-92.

24 Dirven JA, Tange HJ, Muris JW, van Haaren KM, Vink G, van Schayck OC. Early detection of COPD in general practice: patient or practice managed? A randomised controlled trial of two strategies in different socioeconomic environments. Prim Care Respir J. 2013; 22(3): 331-337.

25 Dirven JA, Tange HJ, Muris JW, van Haaren KM, Vink G, van Schayck OC. Early detection of COPD in general practice: implementation, workload and socioeconomic status. A mixed methods observational study. Prim Care Respir J. 2013; 22(3): 338-343.

26 Haroon S, Adab P, Griffin C, Jordan R. Case finding for chronic obstructive pulmonary disease in primary care: a pilot randomised controlled trial. $\mathrm{Br} \mathrm{J}$ Gen Pract. 2013; 63(606): e55-62.

27 Sansores RH, Ramirez-Venegas A, Hernandez-Zenteno R, Mayar-Maya ME, Perez-Bautista OG, Velazquez Uncal M. Prevalence and diagnosis of chronic obstructive pulmonary disease among smokers at risk. A comparative study of case-finding vs. screening strategies. Respir Med. 2013; 107(4): 580-586.

This article is protected by copyright. All rights reserved. 
28 Tinkelman DG, Price D, Nordyke RJ, Halbert RJ. COPD screening efforts in primary care: what is the yield? Prim Care Respir J. 2007; 16(1): 41-48.

29 Dirven JA, Moser A, Tange HJ, Muris JW, van Schayck OC. An innovative COPD early detection programme in general practice: evaluating barriers to implementation. NPJ Prim Care Respir Med. 2014; doi: 10.1038/npjpcrm.2014.55.

30 Haroon S, Jordan RE, Fitzmaurice DA, Adab P. Case finding for COPD in primary care: a qualitative study of the views of health professionals. Int J Chron Obstruct Pulmon Dis. 2015; 10:1711-1718.

31 Kew KM, Dias S, Cates CJ. Long-acting inhaled therapy (beta-agonists, anticholinergics and steroids) for COPD: a network meta-analysis. Cochrane Database Syst Rev. 2014; 3:CD010844.

32 Spencer S, Evans DJ, Karner C, Cates CJ. Inhaled corticosteroids versus longacting beta(2)-agonists for chronic obstructive pulmonary disease. Cochrane Database Syst Rev. 2011; 10: CD007033.

33 Kew KM, Seniukovich A. Inhaled steroids and risk of pneumonia for chronic obstructive pulmonary disease. Cochrane Database Syst Rev. 2014; 3:CD010115.

34 Miravitlles M, de la Roza C, Naberan K, Lamban M, Gobartt E, Martin A. Use of spirometry and patterns of prescribing in COPD in primary care. Respir Med. 2007; 101(8): 1753-1760.

35 Cazzola M, Segreti A, Bettoncelli G, Calzetta L, Cricelli C, Pasqua F, et al. Change in asthma and COPD prescribing by Italian general practitioners between 2006 and 2008. Prim Care Respir J. 2011; 20(3): 291-298.

This article is protected by copyright. All rights reserved. 
36 White P, Thornton H, Pinnock H, Georgopoulou S, Booth HP. Overtreatment of COPD with inhaled corticosteroids--implications for safety and costs: crosssectional observational study. PLoS One. 2013; 8(10): e75221.

37 Johnston KN, Young M, Grimmer-Somers KA, Antic R, Frith PA. Why are some evidence-based care recommendations in chronic obstructive pulmonary disease better implemented than others? Perspectives of medical practitioners. Int J Chron Obstruct Pulmon Dis. 2011; 6:659-667.

38 Young JM, Ward JE. Implementing guidelines for smoking cessation advice in Australian general practice: opinions, current practices, readiness to change and perceived barriers. Fam Pract. 2001; 18(1): 14-20.

39 McLeod D, Somasundaram R, Howden-Chapman P, Dowell AC. Promotion of smoking cessation by New Zealand general practitioners: a description of current practice. $N$ Z Med J. 2000; 113(1122): 480-485.

40 Welte T, Vogelmeier C, Papi A. COPD: early diagnosis and treatment to slow disease progression. Int J Clin Pract. 2015; 69(3): 336-349.

41 Mirkazemi C, Bereznicki LR, Peterson GM. Are the national orthopaedic thromboprophylaxis guidelines appropriate? ANZ J Surg. 2012; 82(12): 913-917.

42 Peterson GM, Boom K, Jackson SL, Vial JH. Doctors' beliefs on the use of antithrombotic therapy in atrial fibrillation: identifying barriers to stroke prevention. Intern Med J. 2002; 32(1-2): 15-23.

43 Bereznicki BJ, Beggs S, Duff C, Bereznicki L. Adherence to management guidelines for childhood asthma in Australia. Aust Fam Physician. 2015; 44(12): 933-938.

This article is protected by copyright. All rights reserved. 
44 Kellerman SE, Herold J. Physician response to surveys. A review of the literature. Am J Prev Med. 2001; 20(1): 61-67.

45 Australian Bureau of Statistics. 1270.0.55.004 - Australian Statistical Geography Standard (ASGS) [homepage on the Internet]: Volume 4 - Significant Urban Areas, Urban Centres and Localities, Section of State, July 2011 [cited: 12 Novemeber 2016]. Available from: http://www.abs.gov.au/ausstats/abs@.NSF/Latestproducts/3353FBEF62DC7586C A257A9800139A0B?opendocument.

This article is protected by copyright. All rights reserved. 
Table 1. Characteristics of responding general practitioners

\begin{tabular}{|l|c|}
\hline Survey item & $\begin{array}{c}\text { Responses } \\
\text { ( }\end{array}$ \\
\hline Gender & \\
\hline Male & $135(57.9 \%)$ \\
\hline Female & $98(42.1 \%)$ \\
\hline Age & $53(26-87)$ \\
\hline Years registered & $29(2-64)$ \\
\hline Location of practice & \\
\hline Urban & $191(82.0 \%)$ \\
\hline Rural & $40(17.2 \%)$ \\
\hline Hours per week seeing patients & $38(6-80)$ \\
\hline Patients seen per week (all) & $120(10-300)$ \\
\hline Patients seen per week (COPD) & $7(1-55)$ \\
\hline Presence of practice nurse(s) in practice & $112(9.3-6)$ \\
\hline Number of full-time equivalent practice nurses & $47(20.2 \%)$ \\
\hline Practice nurses who routinely see patients with COPD & \\
\hline \multirow{2}{*}{ According to Section of State (Australian Bureau of Statistics). }
\end{tabular}

This article is protected by copyright. All rights reserved. 
Table 2. Diagnosis of COPD

\begin{tabular}{|c|c|}
\hline Survey item & $\begin{array}{c}\text { Responses }^{\dagger} \\
(n=233)\end{array}$ \\
\hline \multicolumn{2}{|l|}{ Tools routinely used to diagnosis COPD } \\
\hline Smoking history & $220(94.4 \%)$ \\
\hline Spirometry & $207(88.8 \%)$ \\
\hline Chest x-ray & $154(66.1 \%)$ \\
\hline COPD assessment test & $23(9.9 \%)$ \\
\hline Physical examination & $184(79.0 \%)$ \\
\hline Symptoms & $212(91.0 \%)$ \\
\hline Bronchodilator response & $98(42.1 \%)$ \\
\hline \multicolumn{2}{|l|}{ Spirometry - access } \\
\hline Access to a spirometer & $182(78.1 \%)$ \\
\hline No access to a spirometer, but refer elsewhere & $47(20.2 \%)$ \\
\hline Spirometry - helpful in confirming diagnosis & $229(98.3 \%)$ \\
\hline Recording a formal diagnosis on first presentation & $93(39.9 \%)$ \\
\hline Routinely communicate diagnosis to patient & $204(87.6 \%)$ \\
\hline \multicolumn{2}{|l|}{ Term(s) used to describe diagnosis to patient } \\
\hline Chronic obstructive pulmonary disease / COPD & $159(68.2 \%)$ \\
\hline Other $^{\S}$ & $74(31.8 \%)$ \\
\hline $\begin{array}{l}\text { Routinely schedules a follow-up visit with newly diagnosed } \\
\text { COPD patient }\end{array}$ & $207(88.8 \%)$ \\
\hline
\end{tabular}

${ }^{\dagger}$ Values represent number (percent) of respondents.

This article is protected by copyright. All rights reserved. 
Other times when a formal diagnosis was recorded: after a trial of pharmacotherapy 95 (40.8\%), after a respiratory specialist has diagnosed COPD - 47 (20.2\%), after a hospital discharge $-11(4.7 \%)$.

${ }^{\S}$ Other diagnostic terms: emphysema - 83 (35.6\%), chronic bronchitis - $14(6.0 \%)$, chronic obstructive airways disease $-4(1.7 \%)$, asthma / adult-onset asthma/severe asthma - $3(1.3 \%)$, lung damage - $2(0.9 \%)$, smoker's lungs / smoker's damage - 2 $(0.9 \%)$, chronic airway limitation $-1(0.4 \%)$.

This article is protected by copyright. All rights reserved. 
Table 3. Pharmacological and non-pharmacological management of COPD

\begin{tabular}{|c|c|}
\hline Survey item & $\begin{array}{c}\text { Responses }^{\dagger} \\
(n=233)\end{array}$ \\
\hline Spirometry - helpful in guiding management & $217(93.1 \%)$ \\
\hline \multicolumn{2}{|l|}{ Preferred initial pharmacological management ${ }^{\dagger}$} \\
\hline Tiotropium & $180(77.3 \%)$ \\
\hline Long-acting beta- 2 agonists & $69(29.6 \%)$ \\
\hline Ipratropium & $31(13.3 \%)$ \\
\hline Short-acting beta- 2 agonists & $92(39.5 \%)$ \\
\hline Inhaled corticosteroids (ICS) & $79(33.9 \%)$ \\
\hline Other & $1(0.4 \%)$ \\
\hline Routinely recommend pulmonary rehabilitation & $64(27.5 \%)$ \\
\hline Smoking status routinely recorded & $230(98.7 \%)$ \\
\hline Smoking cessation advice routinely offered & $232(99.6 \%)$ \\
\hline \multicolumn{2}{|l|}{ Timing of initial smoking cessation advice } \\
\hline On first presentation with respiratory symptoms & $182(78.1 \%)$ \\
\hline Later $^{\S}$ & $51(21.9 \%)$ \\
\hline
\end{tabular}

${ }^{\dagger}$ Values represent number (percent) of respondents.

†Other pharmacological management preference: glycopyrronium.

${ }^{\S}$ Other times of smoking cessation advice: at time of diagnosis $-26(11.2 \%)$, at time of follow-up - 16 (6.9\%), whenever a patient expresses an interest in quitting - $7(3.0 \%)$, whenever socially appropriate $-1(0.4 \%)$, after an infective exacerbation $-1(0.4 \%)$.

This article is protected by copyright. All rights reserved. 
Table 4. Use of plans, guidelines, tools and resources

\begin{tabular}{|c|c|}
\hline Survey item & $\begin{array}{c}\text { Responses }^{\dagger} \\
(n=233)\end{array}$ \\
\hline Routinely use General Practice Management Plan (item 721) & $96(41.2 \%)$ \\
\hline Routinely use Team Care Arrangement Plan (item 723) & $85(36.5 \%)$ \\
\hline \multicolumn{2}{|l|}{ Use of management guidelines } \\
\hline Management informed by guidelines & $114(48.9 \%)$ \\
\hline Australian Lung Foundation / COPD-X & $70(30.0 \%)$ \\
\hline Therapeutic Guidelines & $16(6.9 \%)$ \\
\hline Other $^{*}$ & $19(8.2 \%)$ \\
\hline Aware of Australian Lung Foundation's tools and resources & $175(75.1 \%)$ \\
\hline Familiar with Australian Lung Foundation's tools and resources & $17(7.3 \%)$ \\
\hline Routine use of Australian Lung Foundation's tools and resources ${ }^{\S}$ & $114(48.9 \%)$ \\
\hline \multicolumn{2}{|l|}{${ }^{\dagger}$ Values represent number (percent) of respondents. } \\
\hline \multicolumn{2}{|l|}{ ¥Other management guidelines used: international guidelines - 7 (3.0\%), } \\
\hline \multicolumn{2}{|c|}{ colleagues/specialists/professional meetings - 4 (1.7\%), National Asthma Council - 3} \\
\hline \multicolumn{2}{|c|}{ (1.3\%), National Prescribing Service / continuing professional development activities - } \\
\hline \multicolumn{2}{|c|}{$2(0.9 \%)$, pharmaceutical representatives $-1(0.4 \%)$, National Health and Medical } \\
\hline \multicolumn{2}{|c|}{ Research Council - 1 (0.4\%), Symbicort ${ }^{\circledR}$ Maintenance and Reliever Therapy - 1} \\
\hline \multicolumn{2}{|c|}{${ }^{\S}$ Australian Lung Foundation’s tools and resources used: COPD Action Plan - 76} \\
\hline$(32.6 \%)$, Stepwise Management of Stable COPD - 38 (16.3\%), Pri & Care \\
\hline
\end{tabular}

This article is protected by copyright. All rights reserved. 
Table 5. Comparisons between GPs classed as adherent and non-adherent to COPD management guidelines

\begin{tabular}{|c|c|c|c|c|c|c|}
\hline \multirow[t]{2}{*}{ Survey item } & \multicolumn{3}{|c|}{ Univariate analyses } & \multicolumn{3}{|c|}{ Logistic regression } \\
\hline & $\begin{array}{c}\text { Adherent }^{\dagger} \\
(\mathrm{n}=106)\end{array}$ & $\begin{array}{l}\text { Non- } \\
\text { adherent }^{\dagger} \\
(\mathrm{n}=127)\end{array}$ & $\boldsymbol{P}$ & $\begin{array}{l}\text { Odds } \\
\text { ratio }\end{array}$ & $\begin{array}{c}95 \% \\
\text { confidence } \\
\text { interval }\end{array}$ & $\boldsymbol{P}$ \\
\hline $\begin{array}{l}\text { Presence of practice } \\
\text { nurses who routinely } \\
\text { see patients with } \\
\text { COPD }\end{array}$ & $61(57.5 \%)$ & $51(40.2 \%)$ & 0.049 & 1.5 & $0.8-2.7$ & 0.20 \\
\hline $\begin{array}{l}\text { Use "chronic } \\
\text { obstructive } \\
\text { pulmonary disease" } \\
\text { / "COPD" to } \\
\text { describe diagnosis to } \\
\text { patients }\end{array}$ & $79(74.5 \%)$ & $80(63.0 \%)$ & 0.081 & 1.4 & $0.7-2.6$ & 0.30 \\
\hline $\begin{array}{l}\text { Routinely use } \\
\text { General Practice } \\
\text { Management Plan } \\
\text { (item 721) }\end{array}$ & $56(52.8 \%)$ & $40(31.5 \%)$ & 0.002 & 0.9 & $0.3-2.9$ & 0.86 \\
\hline $\begin{array}{l}\text { Routinely use Team } \\
\text { Care Arrangement } \\
\text { Plan (item 723) }\end{array}$ & $52(49.1 \%)$ & $33(26.0 \%)$ & $<0.001$ & 2.0 & $0.6-6.8$ & 0.26 \\
\hline Management of & $62(58.5 \%)$ & $52(40.9 \%)$ & 0.013 & 1.5 & $0.8-2.7$ & 0.20 \\
\hline
\end{tabular}

This article is protected by copyright. All rights reserved. 
